\title{
Investigation of formaldehyde removal from synthetic contaminated air by using human hair
}

\author{
Amirreza Talaiekhozani ${ }^{1 *}$, Mohammad Reza Talaei ${ }^{2}$, Mehdi Yazdan $^{3}$, Seyed Masoud Mir ${ }^{3}$ \\ ${ }^{1}$ Assistant Professor, Department of Civil Engineering, Jami Institute of Technology, Isfahan, Iran \\ ${ }^{2}$ Associate Professor, Department of Chemical Engineering, Faculty of Engineering, University of Isfahan, Isfahan, Iran \\ ${ }^{3}$ BSc Student, Department of Chemical Engineering, Jami Institute of Technology, Isfahan, Iran
}

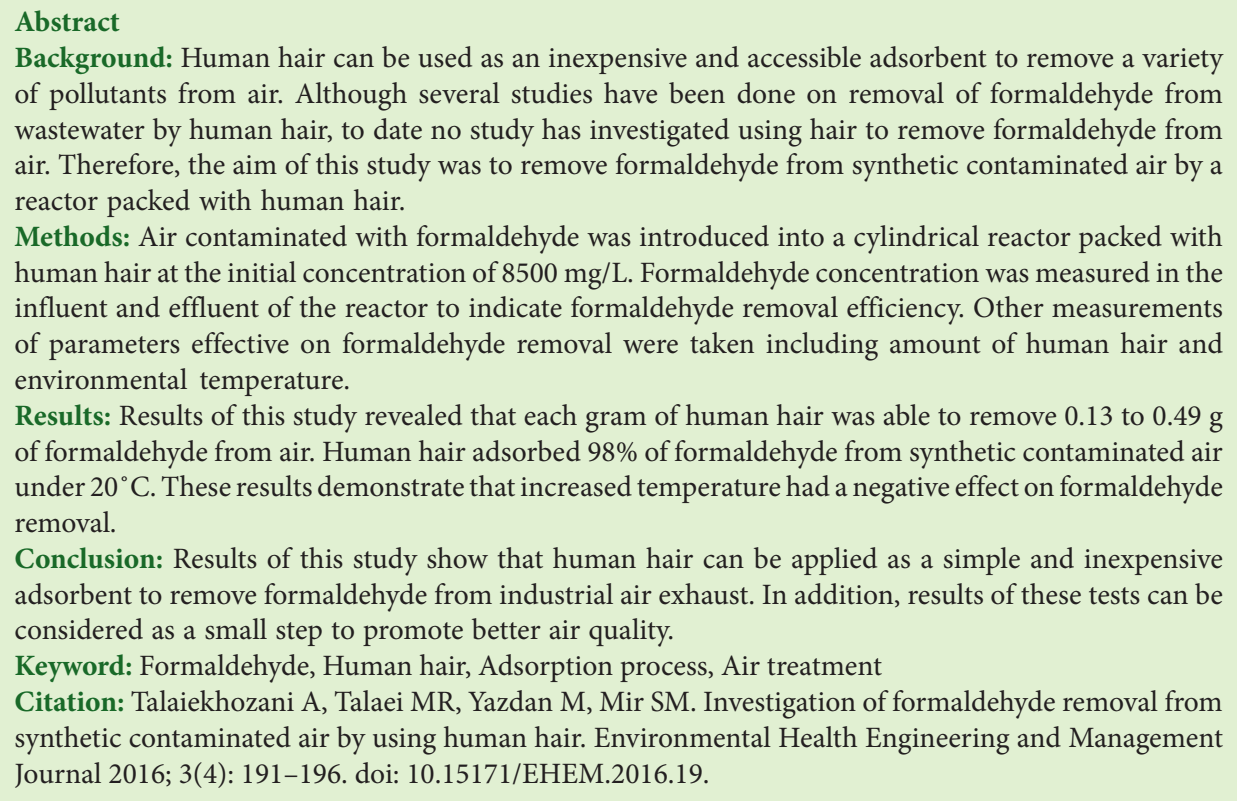

\section{Introduction}

Nowadays, industry produces many different pollutants in the form of gases, liquids and solids, which are released into the environment (1-3). Therefore, it is essential to control emissions of wastewater, exhausted gases and solid waste by developing treatments methods for application before they are released $(2,4,5)$. Exhausted gases emitted from industry contribute to air pollution (6). Several air pollutants are harmful to humans by causing cancer or infertility (7). Air treatment is more complex than wastewater or solid waste treatment and needs more developed technology $(8,9)$. Formaldehyde is widely used in industry and released into the atmosphere where it is a pollutant (10). Formaldehyde is a highly toxic, teratogenic, carcinogenic and mutagenic substance and thousands of tons are released into the atmosphere yearly (11). Formaldehyde can be absorbed from the air into seas and oceans where it generates water pollution. Formaldehyde is a basic chemical used in the production of keratin-based hair smoothing products. Formaldehyde is a listed dangerous chemical (1-3). This causes some manufacturers, importers, or distributors use other terms for chemical formaldehyde on their product information. There are many alternative terms used for formaldehyde including methylene glycol, formalin, methylene oxide, paraform, formic aldehyde, methanal, oxomethane, oxymethylene, timonacic acid or CAS No. 50-00-0 (12). These alternative terms mean that some products are labeled and marketed as formaldehyde free. Workers in beauty salons breathe in the formaldehyde released from such hair smoothing products or they may absorb it through their skin. Workers in beauty salons are exposed to formaldehyde during all hair straightening processes, particularly if the temperature is increased by use of tools such as during blow-drying or flat ironing processes (1). Occupational Safety and Health Administration (OSHA) recommends the maximum concentration of formaldehyde in air at 0.15 and 8 hours exposure is 2 
and $0.5 \mathrm{ppm}$, respectively (13). In addition, the American Conference of Governmental Industrial Hygienists reports the threshold limit value ceiling of formaldehyde at $0.3 \mathrm{ppm}$ (11).

Although several studies have been done on formaldehyde removal from wastewater (9); there has been very little research on removal of this dangerous substance from air. Methods of formaldehyde removal from air can be divided into three categories; physical, chemical and biological methods. In physical methods, formaldehyde is degraded to water and carbon dioxide by increasing the temperature to above $550^{\circ} \mathrm{C}$. Although this method is effective to remove formaldehyde from the air, it is expensive and generates secondary pollutants such as carbon dioxide (5). Biological methods have also been used to remove formaldehyde from air. In biological methods, microorganisms are adapted to consume formaldehyde as their sole source of carbon. Biological methods are inexpensive but their operation is very complex.

Adsorption is another method for formaldehyde removal from air. Adsorption is an effective method and partially inexpensive for formaldehyde removal from air such that its operation is not as complex as biological methods. Various adsorbents have been introduced to remove pollutants from air and research has shown that human hair can be applied a natural adsorbent. Talaie et al applied human hair to remove formaldehyde from industrial wastewater (1). It was reported that this hazardous substance was adsorbed chemically onto human hair (1). Ghanbarnejad et al reports that both sheep wool and human hair were suitable for removing formaldehyde from water (9). They also report that formaldehyde was chemically adsorbed onto both sheep wool and human hair. In addition, increasing temperature had a destructive effect on adsorption of formaldehyde onto sheep wool and human hair (9). Rostami reports an investigation of removal of cadmium and lead from aquatic environments by human hair (14). This result showed that adsorption of cadmium onto human hair was higher than that of lead.
Rostami reports that human hair was able to remove 38 mg cadmium per each gram human hair. It was reported that treatment of human hair by $0.1 \mathrm{M} \mathrm{NaOH}$ and $\mathrm{Na}_{2} \mathrm{~S}$ solution significantly increased adsorption of both cadmium and lead (14). However, treatment of human hair by this solution had some disadvantages such as a malodorous emission and caused breaking - up of human hair.

Although several of studies have been done on formaldehyde removal from wastewater by human hair, it has not been tested to date as an adsorbent to remove formaldehyde from air. Therefore, the aim of this study was to investigate removal of formaldehyde from air and to determine its effective factors including amount of hair and temperature. In this study, an adsorption reactor containing human hair was prepared and synthetic contaminated air was introduced to evaluate formaldehyde removal from air.

\section{Methods and Materials}

The pilot plant

The pilot plant used in this study is depicted in Figure 1. Formaldehyde-contaminated air was synthesized by bubbling fresh air through $37 \%$ formaldehyde solution. The bubble column was maintained until the outgoing air stream became saturated with formaldehyde. The synthetic contaminated air was passed through an adsorption bed packed with human hair. Formaldehyde was adsorbed onto the human hair, and the treated air then left the adsorption bed column. Flow rate of the incoming air stream was measured using a flow meter. The adsorption column was a polyethylene cylinder $50 \mathrm{~cm}$ long and 8 $\mathrm{cm}$ in diameter. The adsorption reactor temperature was adjusted by a water batch (Figure 1). The water batch temperature was maintained at the desired value by an electrical temperature controller with accuracy of $\pm 1^{\circ} \mathrm{C}$.

The effects of influencing parameters

In this study, the effects of the parameters amount of human

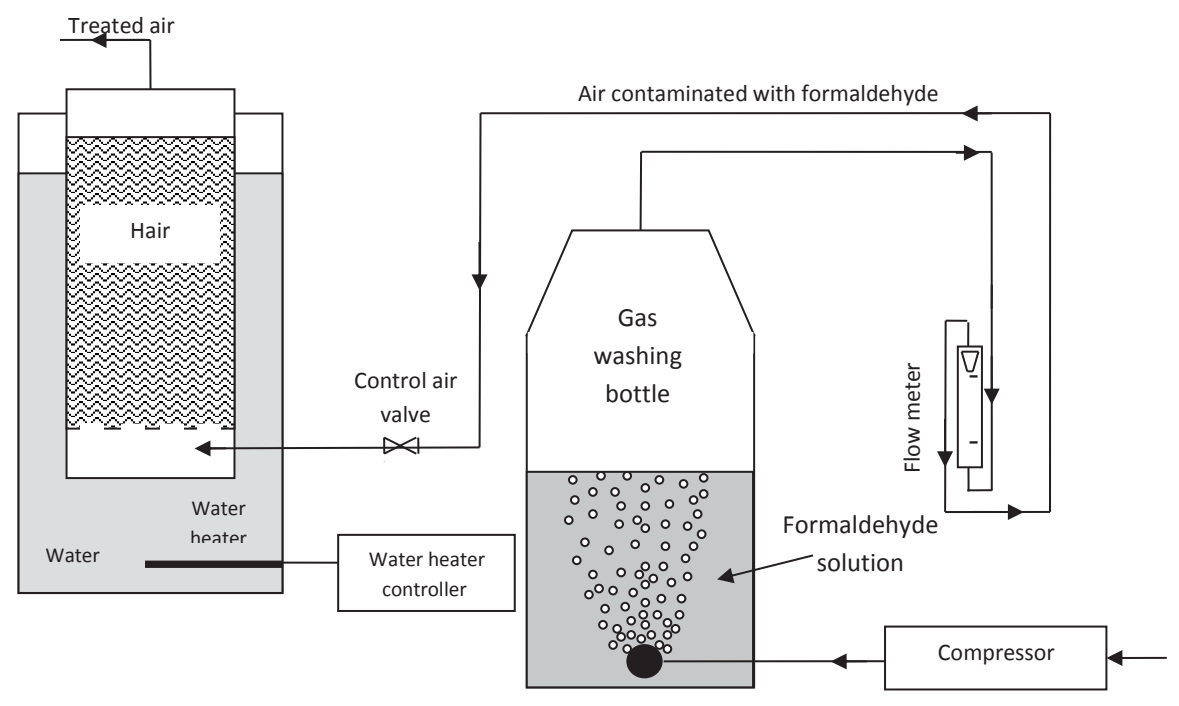

Figure 1. Schematic of the pilot planet. 
hair and temperature were evaluated on formaldehyde removal. This evaluation is explained in the following section. There was no replicate for the experiments in this study.

\section{Amount of human hair}

The amount of human hair used in the adsorption reactor was changed to investigate its effect on formaldehyde removal. The formaldehyde removal efficiency of adsorption reactor containing 20,30, 40 and $50 \mathrm{~g}$ of human hair was determined in 100 minutes. Eq. 1 was used to calculate formaldehyde removal efficiency.

$R E=\left(\frac{C_{\text {out }}-C_{\text {in }}}{C_{\text {out }}}\right) \times 100$

where, $R E$ is formaldehyde removal efficiency in $\%, C_{i n}$ is formaldehyde concentration in influent air in $\mathrm{mg} / \mathrm{L}$ and $C_{\text {out }}$ is formaldehyde concentration in effluent air in $\mathrm{mg} / \mathrm{L}$.

\section{Temperature}

Figure 1 shows the adsorption reactor immersed into a water tank equipped with a temperature controller. Temperature of adsorption reactor was adjusted on the 20, 30,40 and $50^{\circ} \mathrm{C}$. Formaldehyde removal efficiency was determined for all temperatures.

\section{Batch experiment}

The removal of formaldehyde using human hair was investigated in batch mode. A special bottle was prepared for the batch experiment (Figure 2). The bottle was loaded by a given mass of human hair that was initially placed in an enclosed and sealed storage tank with a remote control opening door. When the remote control door opened, then the human hair was exposed to the air captured in the bottle, and the adsorption process began. Two steps were taken for the batch experiment; the first step was continual

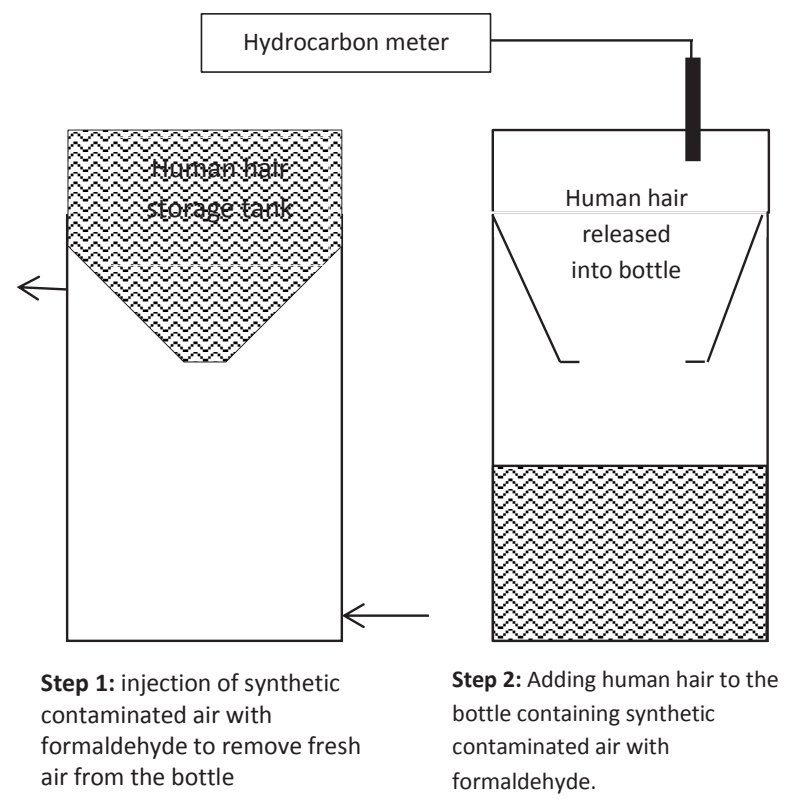

Figure 2. Schematic of batch experiment. injection of synthetic air contaminated by formaldehyde into a bottle for 5 minutes to sweep all initial fresh air inside the bottle and the second step was release of human hair into the bottle by opening the remote control door to begin the adsorption process. A continuous record was made of formaldehyde concentration equilibrium by digital hydrocarbon meter.

\section{Analytical methods}

Formaldehyde concentration was measured in the air streams by a digital hydrocarbon meter Testo 330-1G-KIT4. Ambient temperature was determined by alcoholic thermometer. Microsoft Excel was used for plotting the graphs and mathematical calculations.

\section{Results}

Continuous mode

Figure 3 shows the break-through curves obtained for hair mass loadings of 20 to $40 \mathrm{~g}$. It is common knowledge that the break-through curve is independent of the adsorbent mass of loading if all conditions; flow rate, temperature, bed void fraction and inlet concentration are the same. However, the fact remains that when the bed length allows the mass transfer zone then there is ample time for the development process. As can be seen in this figure the break-through curves for adsorbent masses of 20 and $30 \mathrm{~g}$ were different with those of 40 and $50 \mathrm{~g}$. Also, the breakthrough curves obtained for adsorbent mass of $40 \mathrm{~g}$ was very close to that of $50 \mathrm{~g}$. This demonstrates that for an adsorbent mass of $40 \mathrm{~g}$ or more then there was adequate time for mass transfer zone to be developed.

The temperature of the adsorption reactor containing human hair was adjusted on the $20,30,40$ and $50^{\circ} \mathrm{C}$ to evaluate its effect on formaldehyde removal. The results of temperature effect on formaldehyde removal are shown in Figure 4 as a break-through curve. As can be seen in this figure, an increase in temperature had an adverse effect on formaldehyde removal.

Batch mode

In the batch experiment, the aim was to obtain an isotherm for formaldehyde-human hair adsorption system in the

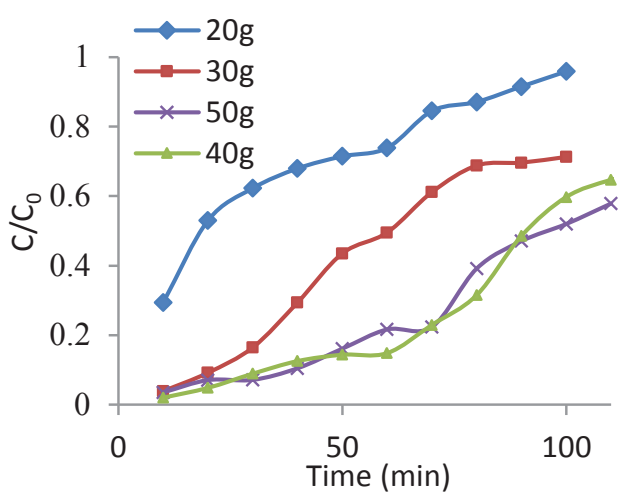

Figure 3. The break-through curve of the continuous adsorption process in a packed bed for different masses of human hair. 
gas phase. The result of this study is shown in Figure 5 as an isotherm at temperature of $20^{\circ} \mathrm{C}$.

\section{Discussion}

The results of this study reveal that the saturation adsorption capacity of human hair ranged from 0.049 to $0.13 \mathrm{~g}$ formaldehyde/g of hair; and results were dependent on temperature. It is the maximum capacity and may not always be attainable in practice. The continuous adsorption process was carried out using a bed packed with a load of

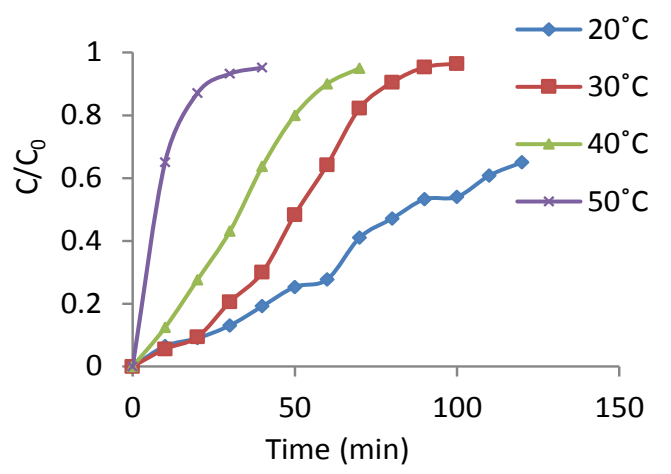

Figure 4. Break-through curve of the continuous adsorption process in a packed bed for different temperature.

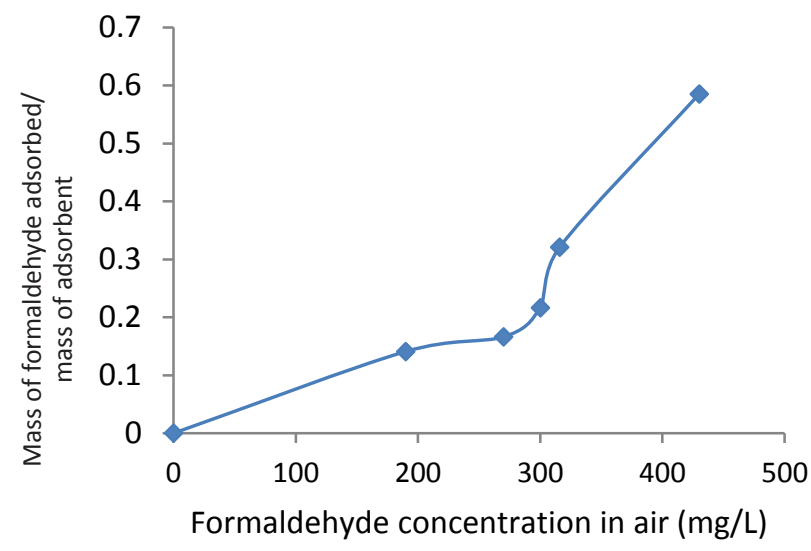

Figure 5. Mass of formaldehyde adsorbed/mass of adsorbent versus formaldehyde concentration in air. adsorbent. When the adsorption process had begun, the mass transfer zone started forming and after complete development (which will occur if the bed has adequate length) it moves through the bed. When this zone reaches the end of the bed the pollutant concentration starts rising and ends up as inlet concentration. Saturation occurs when the outlet concentration becomes close to that of the inlet concentration. However, if there is a restriction on the outlet concentration, then the operation should stop well before this time. It means that when the operation ceases, the bed is not completely saturated. The complete continuous adsorption process is performed though successive adsorption-regeneration cycles. Unfortunately, no documents have been published to date on methods of human hair adsorbent regeneration. Therefore, human hair must be frequently replaced to maintain the formaldehyde removal efficiency at its highest level. As such, the results shown in Figure 3 reveal that, under the conditions applied in this experiment, at least $40 \mathrm{~g}$ of human hair must be used for mass transfer zone to be developed.

Hair is composed of a protein known as keratin. Formaldehyde has a high reactivity towards proteins (1). Formaldehyde is able to react with different side chains of amino acids such as the amino groups of lysine, arginine, glutamine and asparagine. Formaldehyde can form crosslinks with keratin, such as $\mathrm{NH}-\mathrm{CH}_{2}-\mathrm{NH}$ bridges, and between $\mathrm{N}$-terminal cysteine and amine groups $-\mathrm{S}-\mathrm{CH}_{2}-\mathrm{NH}$ (15). The best $\mathrm{pH}$ for the reaction between formaldehyde and keratin is 6 to 7 . Amide derivatives of aspartic acid and glutamic acid react with formaldehyde. Some of these reactions can be bi-functional and mono-functional. The simple crosslinks are $\mathrm{CH}_{2}$. It is very difficult to locate the active sites and the extent of formaldehyde keratin reactions because most modified side chains of amino acids are not stable to hydrolytic reaction conditions (16). Reaction between keratin and formaldehyde was divided into two steps. The first step involved amino groups and formaldehyde and produced an unstable product (aminomethylol derivative). The second reaction led to a stable methylene bridge (17). The vapor pressure of the formaldehyde at $20^{\circ} \mathrm{C}$ is 3285

Reaction step 1:

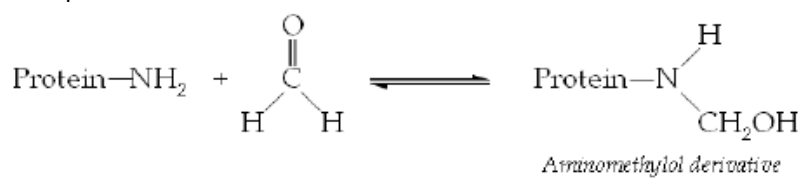

Reaction step 2:

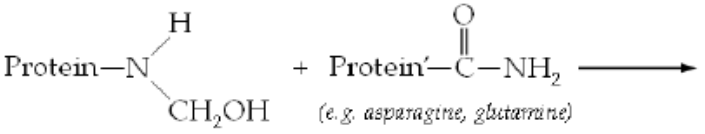

$$
\begin{aligned}
& \longrightarrow \text { Protein- } \underset{\text { Methylere brage }}{\stackrel{\mathrm{CH}}{\mathrm{CH}_{2}-\mathrm{NH}-\stackrel{\mathrm{C}}{\mathrm{O}}-\text { Protein' }}+\mathrm{H}_{2} \mathrm{O}}
\end{aligned}
$$


$\mathrm{mm} \mathrm{Hg}$. This means that there was no opportunity for the formaldehyde vapor to be condensed in the conditions applied throughout the experiments. Thus, formaldehyde removal was not by condensation.

The results shown in Figure 4 demonstrate that adsorption capacity increased as temperature was reduced. This fact is in line with the characteristics of physical adsorption, which is in contrast with the literature provided in the preceding section. In other words, in a chemical adsorption process, adsorption capacity is usually decreased by temperature. However, chemical adsorption can be considered as a two-step process. In the first step, contamination is adsorbed on the surface of an adsorbent physically in the form of adsorbate. Then, adsorbate undergoes a series of reactions with human keratin as afore-mentioned. Therefore, if the rate of the first step was controlling, then the adsorption capacity can be reduced by temperature even though the adsorption process falls into the category of chemical adsorption.

Based on these results, an empirical equation was developed to calculate the amount of human hair needed for removal of formaldehyde from an air stream (Eq. 2). $w=r \times Q \times c \times t$

where, $r$ is the amount of formaldehyde which can be removed by $1 \mathrm{~g}$ of human hair in $\mathrm{g} / \mathrm{g}, w$ is the mass of human hair that is utilized for removal of formaldehyde from an air stream in $\mathrm{g}, Q$ is air flow rate in $\mathrm{m}^{3} / \mathrm{h}, c$ is inlet formaldehyde concentration in $\mathrm{g} / \mathrm{m}^{3}$ and $t$ is desired filtering time in hour. The coefficient of $r$ was obtained ranging from 0.049 to 0.13 and can be estimated by Eq. 3, as follows:

$r=9 \times 10^{-6} \times T^{3}+0.008 \times T^{2}-2.44 \times T+244.8$

where, $T$ is temperature in $K$. It should be mentioned that Eq. 3 is valid only for temperatures between 20 and $60^{\circ} \mathrm{C}$.

\section{Conclusion}

Formaldehyde is a toxic, mutagenic, teratogenic and suspected carcinogenic chemical that is highly reactive with proteins such as keratin. Therefore, formaldehyde can be removed from air by an adsorption reactor packed with human hair. Results of this study revealed that each gram of human hair was able to remove from 0.13 to 0.49 $\mathrm{g}$ of formaldehyde from air. Human hair adsorbed $98 \%$ of formaldehyde form synthetic contaminated air under $20^{\circ} \mathrm{C}$. In addition, results illustrated that increased temperature had a distractive effect on formaldehyde removal by human hair. Although formaldehyde removal by human hair presents an effective method to treat contaminated air, economic calculations are needed to reveal determine whether or not this process is economically viable on a larger scale.

\section{Acknowledgments}

This article has been extracted from a Bachelor of Science dissertation in field of chemical engineering at Jami Institute of Technology, Isfahan, Iran. The authors of this article appreciate the Jami Institute of Technology for its financial and moral support, which enabled completion of this dissertation.

\section{Ethical issue}

Authors are aware of, and comply with the best practice in publication ethics specifically with regard to authorship (avoidance of guest authorship), dual submission, manipulation of figures, conflict of interests and compliance with policies on research ethics. The authors adhere to publication requirements that submitted work is original and has not been published elsewhere in any language.

\section{Competing interests}

The authors declare that there is no conflict of interest that would prejudice the impartiality of this scientific work.

\section{Authors' contributions}

All authors of this study have a complete contribution for data collection, data analyses and manuscript writing.

\section{References}

1. Talaie AR, Bagheri M, Ghotbinasab S, Talaie MR. Evaluation of formaldehyde wastewater adsorption on human hair. Health Syst Res 2011; 6(4): 735-743. [In Persian].

2. Talaiekhozani A, Talaie MR, Fulazzaky MA. Evaluation of formaldehyde removal from contaminated air by using a biotrickling filter reactor in a continuous condition. Journal of Air Pollution and Health. 2016;1(2):69-76.

3. Talaiekhozani A, Masomi B, Hashemi SMJ. Evaluation of gaseous pollutants emission rate from Marvdasht landfills. J Adv Med Sci Appl Tech 2016; 2(1): 162-75.

4. Talaiekhozani A, Bagheri M, Najafabadi NR, Borna E. Effect of nearly one hundred percent of municipal solid waste recycling in najafabad city on improving of its air quality. J Air Pollut Health 2016; 1(2): 111-22.

5. Talaiekhozani A, Bagheri M, Goli A, Talaie Khoozani MR. An overview of principles of odor production, emission, and control methods in wastewater collection and treatment systems. J Environ Manage 2016; 170: 186-206. doi: 10.1016/j.jenvman.2016.01.021.

6. Talaiekhozani A, Ali Fulazzaky M, Ponraj M, Abd Majid M. Removal of formaldehyde from polluted air in a biotrickling filter reactor. Desalination and Water Treatment 2014; 52(19-21): 3663-71. doi: 10.1080/19443994.2013.854002.

7. Alaee S, Talaiekhozani A, Ziaei GR, Lohrasbi P. Evaluation of Iranian college students' awareness about infertility risk factors. Jundishapur J Health Sci 2016; 8(2): e34172. doi: 10.17795/jjhs-34172.

8. Fulazzaky MA, Talaiekhozani A, Ponraj M, Abd Majid MZ, Hadibarata T, Goli A. Biofiltration process as an ideal approach to remove pollutants from polluted air. Desalination and Water Treatment 2013; 52(19-21): 360015. doi: 10.1080/19443994.2013.854102.

9. Ghanbarnejad P, Goli A, Bayat B, Barzkar H, Talaiekhozani A, Bagheri M, et al. Evaluation of formaldehyde adsorption by human hair and sheep wool in industrial wastewater with high concentration. J Environ Treat Tech 2014; 2(1): 12-7.

10. Fulazzaky MA, Talaiekhozani A, Hadibarata T. Calculation of optimal gas retention time using a logarithmic equation applied to a bio-trickling filter reactor for formaldehyde 
removal from synthetic contaminated air. RSC Adv 2013; 3(15): 5100-7. doi: 10.1039/C3RA22753G.

11. Talaiekhozani A, Fulazzaky MA, Ponraj M, Majid ZA. Formaldehyde from production to application. 3rd Conference of Application of Chemistry in Novel Technologies; November 7, 2013; Isfahan. Iran. p. 1-16.

12. Hazard Alert: Hair Smoothing Products That Could Release Formaldehyde. OSHA; 2016 [cited 10 September 2016]. Available from: https://www.osha.gov/SLTC/ formaldehyde/hazard_alert.html.

13. Formaldehyde Program: Environmental Health and Safety at UVM. UVM; 2016 [cited 10 September 2016]. Available from: http://www.uvm.edu/safety/formaldehyde.

14. Rostami S. Application of human hair to remove heavy metals from aquatic environments (Cadmium and lead) [dissertation]. Isfahan: Jami Institute of Technology; 2001.

15. Hinton EH. A survey and critique of the literature on crosslinking agents and mechanisms as related to wool keratin. Text Res J 1974; 44(4): 233-92. doi: 10.1177/004051757404400401.

16. Simpson WS. Wool chemistry. Wool. A volume in Woodhead Publishing Series in Textiles. 2002; 130-159. doi: 10.1533/9781855737648.130.

17. Wortmann G, Sweredjuk Thome R, Sweredjuk G, Zwiener G, Wortmann FJ. Chemisorption of protein reactive indoor air pollutants by wool. 12th International Conference on Renewable Resources and Plant Biotechnology. June 12-13, 2006, Magdeburg, Germany. 